\title{
Seroprevalence of HIV, hepatitis B, and syphilis in an urban population and isolated villages in Gabon
}

\begin{abstract}
Introduction
In the past Gabon had one of the lowest fecundity rates in Africa and genital infections have been demonstrated as having a major role. ${ }^{1}$ Public health efforts have been made to reduce the impact of sexually transmitted diseases (STDs), but they have not concerned isolated communities where healthcare provision is commonly lacking.
\end{abstract}

\section{Method}

Using a cluster sampling method, a representative sample of 456 adults living in the town of Franceville (30 000 inhabitants) was compared with the 211 adults living in five gold panning villages in the Nouna area.

At the beginning of 1996, sociodemographic characteristics were gathered and a blood sample was taken for testing for the following:

(1) HIV-screening by enzyme immunoassay (Genelavia mixt Sanofi-Pasteur, Marnes-la-Coquette, France and Enzygnost Anti-HIV 1/2 Plus, Behring, Marburg, Germany). Differentiation between HIV-1 and HIV-2 with a third enzyme immunoassay (Multispot HIV-1/ HIV-2, Sanofi-Pasteur, Marnes-la-Coquette, France).

(2) Hepatitis B-detection of $\mathrm{Ag} \mathrm{HBs}$ by enzyme immunoassay (Monolisa $\mathrm{Ag}$ HBs, Sanofi-Pasteur, Marnes-laCoquette, France).

(3) Syphilis-Treponema pallidum haemagglutination assay (TPHA-kit Biomerieux, Marcy-l'Etoile, France).

The data were analysed using the $\chi^{2}$ test, the Fisher's exact test, and the MantelHaenszel $\chi^{2}$ test for stratified analysis. Prevalence was estimated with a confidence

Table 1 Seroprevalence rates (in \%) of three STDs, among two general populations of adults living

in Gabon, in 1996

\begin{tabular}{|c|c|c|c|c|c|c|c|c|c|}
\hline & \multicolumn{4}{|c|}{ Franceville } & \multicolumn{4}{|c|}{ Nouna } & \multirow[b]{2}{*}{$F v N$} \\
\hline & $n$ & $M$ & $F$ & $S \mathrm{~Pa}^{\star}$ & $n$ & $M$ & $F$ & $\mathrm{SPa}^{\star}$ & \\
\hline HIV 1 & 453 & $1.0(02)$ & $2.7(07)$ & 1.8 & 207 & $1.4(2)$ & $4.8(03)$ & 3.0 & $p>0.05$ \\
\hline HBV & 442 & $11.5(22)$ & $14.5(39)$ & 13.6 & 211 & $27.7(41)$ & $11.1(07)$ & 19.4 & $\mathrm{p}>0.05$ \\
\hline Syphilis & 452 & $5.6(11)$ & $11.0(28)$ & 8.3 & 209 & $24.0(35)$ & $27.0(17)$ & 25.5 & $\chi^{2}=31.8 p<0.001$ \\
\hline
\end{tabular}

Figures in parentheses $=$ number of positive cases.

$\star$ Seroprevalence adjusted by sex.

interval of $95 \%$. The observed differences were considered as significant for an alpha error of $5 \%$. The seroprevalence rates were adjusted by sex.

\section{Results}

The seroprevalence rates for HIV are not significantly different in the two population (table 1), and remain lower than in the capital, Libreville $(3.7 \%$ among the blood donors in 1995). In Franceville, the seroprevalence rate of HIV-1 has doubled since the last similar survey in $1988 .^{2}$ During the same time, this rate has multiplied by only 1.3 in Libreville. The HIV seroprevalence in the two populations and, more generally in Gabon, stays relatively low compared with the seroprevalence commonly noted in Central Africa. No HIV-2 was found during these surveys, confirming its very low seroprevalence in Gabon. ${ }^{3}$

The population at risk for hepatitis $\mathrm{B}$ is different in the two sites. In Franceville, the risk of being $\mathrm{Ag} \mathrm{HBs}$ positive is greater for west Africans than for central Africans (7/20 v 53/419, $\mathrm{RR}=2.77,95 \% \mathrm{CL}=1.45-5.29$ ), but this risk exists only for women cohabiting. So it is mainly the social status of these immigrant women that exposes them to the risk of contamination-cloistered at home, with little access to prevention and treatment, they are the inevitable victims of the extraconjugal contaminations of their husband. In the villages, trading is the risk factor but only among men $(13 / 31 v 28 / 118, \mathrm{RR}=1.83,95 \%$ $\mathrm{CL}=1.08-3.08)$. It could be proposed that travelling to the city to restock would permit a man to have more sexual partners than a woman.
The seroprevalence rate of syphilis in Franceville is low for a central African city. ${ }^{45}$ This seroprevalence was $13.3 \%$ in $1987^{6}\left(\chi^{2}=\right.$ $4.68, \mathrm{p}<0.05)$. The actual low seroprevalence could be the result of the joint action of the hospital and the International Center for Medical Research at Franceville: 5000 women attending prenatal consultation have been tested annually and eventually treated, as were their partners, since 1984

\section{Discussion}

The seroprevalence rate in the villages is three times greater than that in Franceville. The role of non-venereal syphilis cannot be neglected. No cases of yaws have been notified in Franceville for 20 years. Epidemiological data concerning a remote area such as Nouna are not available, but environmental factors appear more favourable to the ongoing endemicity of yaws. However, this kind of lesion was not seen among the study population.

E BERTHERAT

R NABIAS

M C GEORGES-COURBOT

A RENAUT

Centre International de Recherches Médicales de Franceville, Gabon

Correspondence to: Eric Bertherat, Service de Médecine des Collectivités, Hôpital d'Instruction des Armées A Laveran, 13998 Marseille Armées, France.

1 Collet M, Reniers J, Frost E, et al. Infertility in central Africa: infection is the cause. Int $f$ Gynaecol Obstet 1988;81:423-8.

2 Schrijvers D, Josse $\mathrm{R}$, Trebucq A, et al. Transmission of syphilis between sexual partners in Gabon. Genitourin Med 1989;65:84-5.

ners in Gabon. Genitouin Med 1989;65:84-5. Louis JP, Trebucq A, Hamono B, et al. Situation de l'infection à VIH à Libreville, Gabon Evolution de 1986 à 1991. Ann Soc Belge Méd
Trop 1992;72:233-5.

Wagner HU, Van Dyck E, Roggen E, et al. Seroprevalence and incidence of sexually transmitted diseases in a rural Ugandan population. Int f STD AIDS 1994;5:332-7.

5 Louis JP, Gardon J, Trebucq A, et al. Particularités épidémiologiques de l'infection rétrovirale à HTLV-1 en Afrique Centrale. Bull Soc Pathol Exot 1993;86:163-8.

6 Dupont A, Schrivers D, Delaporte E, et al. Séroprévalence de la syphilis dans des populations urbaines et semi-rurales du Gabon. Bull Soc Pathol Exot Filiales 1988;81:699-704. 